Cleary, M., Jackson, D., Woods, C., Kornhaber, R., Sayers, J. and Usher, K. (2016) 'Experiences of health professionals caring for people presenting to the emergency department after taking crystal methamphetamine ("ICE")', Issues in Mental Health Nursing, 38 (1), pp. 33-41.

DOI: https://doi.org/10.1080/01612840.2016.1251516

This document is the authors' Accepted Manuscript.

License: https://creativecommons.org/licenses/by-nc-nd/4.0

Available from RADAR: https://radar.brookes.ac.uk/radar/items/8152e66a-d3fd-45d3-a966-6d4c70704598/1/

Copyright $(\subseteq$ and Moral Rights are retained by the author(s) and/ or other copyright owners unless otherwise waved in a license stated or linked to above. A copy can be downloaded for personal non-commercial research or study, without prior permission or charge. This item cannot be reproduced or quoted extensively from without first obtaining permission in writing from the copyright holder(s). The content must not be changed in any way or sold commercially in any format or medium without the formal permission of the copyright holders. 


\title{
TITLE: Experiences of health professionals caring for people presenting to the emergency department after taking crystal methamphetamine ('ICE')
}

\begin{abstract}
Globally addiction to 'ICE' (crystal methamphetamine) is increasing presenting emergency health care services personnel with a number of challenges. This paper reports the first of two major themes arising from a qualitative study investigating health professionals' experiences' managing people presenting to the Emergency Department (ED) after taking 'ICE'. The theme 'Caring for people who use 'ICE' when presenting to EDs' comprises five subthemes. These are: (i) expecting the unexpected: “they're just off their heads"; (ii) complexity of care: 'underlying trauma and emotional dysregulation'; (iii) connecting and relationships: 'engaging in a calm and helpful way'; (iv) coordinating care and teamwork: keeping them quiet and away from everybody' and (v) learning and reflection: 'we need to rethink our treatment options'. These findings highlight the complexity and resource-intensity associated with providing emergency care to persons affected by ICE, and the need for thoughtful strategies that can further develop the capacity and capability of health professionals to provide optimal care to people using ICE.
\end{abstract}

KEY WORDS: addiction, behaviour, emergency departments, health professionals, 'ICE', qualitative research, mental health, mental health nursing, methamphetamine, street drugs. 


\section{TITLE: Experiences of health professionals managing people presenting to the emergency department after taking crystal methamphetamine ('ICE')}

\section{INTRODUCTION}

Multiple forms of methamphetamine have been widely available in Australia since the 1990s. There are different forms of amphetamine-type substances and these have different names (Maxwell, 2005). 'ICE', also known as 'Crystal' or 'crystal meth', is the crystalline form of methamphetamine; a highly addictive psycho-stimulant with longer-lasting physical effects and it is commonly injected or smoked (Commonwealth of Australia, 2015). Users of this purer form of methamphetamine report more frequent methamphetamine use and higher levels of dependence (Australian Institute of Health and Welfare, 2014; Kinner, Kinner, Degenhardt, Kinner, \& Degenhardt, 2008).

The number of people in Australia using methamphetamines weekly has grown from $9.3 \%$ in 2010 to $15.5 \%$ in 2013 (Australian Institute of Health and Welfare, 2014). While there was not a significant increase in methamphetamine use overall from 2010 to 2013 , there was a change in use from other forms to smoking of crystal methamphetamine. Daily or weekly 'ice' use has doubled from $12.4 \%$ in 2010 to $25 \%$ in 2013. Proportionally, Australia has higher rates of methamphetamine use than other countries and the evidence suggests over 200,000 Australians are ICE users and this is a conservative figure (Commonwealth of Australia, 2015).

Around $2.5 \%$ of Australians aged 14 years (about half a million people) have used methamphetamines, which is 3-5 times higher than the rate for the USA, Canada or the UK (Lee, 2013). 'ICE' use is reported to be on the increase in Australia particularly among ecstasy users and those using other injectable drugs (Commonwealth of Australia, 2015; Degenhardt et al., 2008). The percentage of ecstasy users also using 'ICE' almost doubled 
from $15 \%$ in 2009 to $20 \%$ in 2012 whilst 'ICE' use among people who inject other drugs rose from $37 \%$ in 2009 to $54 \%$ in 2012 (Heilbronn, 2013).

Emergency service callouts and presentations to hospitals where methamphetamines were the principal drug of concern have increased extensively as have arrests for methamphetamine related crime (Lee, 2015). Callouts for ambulances to attend people who have used 'ICE' in one Australian city rose from 136 in 2009/10 to 592 in 2011/12 (Lloyd, Matthews, \& Gao, 2014).

Methamphetamine is a commonly abused stimulant, and is associated with a high number of Emergency Department (ED) presentations (7.6\% of psychiatric ED visits) and may produce psychiatric symptoms such as acute psychosis, depression, and anxiety disorder (Cloutier, Hendrickson, Fu, \& Blake, 2013). The user's behaviour is affected, with people affected by 'ICE' demonstrating fear and aggressive and violent outbursts, and the psychosis-like symptoms associated with methamphetamine use resemble those seen with paranoid schizophrenia (Grant et al., 2012). As a consequence, the 'ICE' user may represent a danger not only to themselves but to others such as family, friends, members of the public, police or health professionals (Clark, 2008). In a prospective observational study of toxicology-related presentations to the $\mathrm{ED}$, methamphetamine users were reported to be more aggressive, violent and dangerous than users of other drugs, and were using methamphetamine consistently (Bunting, Fulde, \& Forster, 2007). As the incidence and patterns of 'ICE' use increase there is a need for evidence-based interventions across the continuum of care to ensure the best possible patient care, as well as the safety of the patient, and those with whom they interact.

Whist anecdotal evidence from emergency services indicates an alarming increase rise in the use of ice (Commonwealth of Australia, 2015), little is known about the experiences of health professionals working with people who use 'ICE' and subsequently require emergency health services care. This paper reports on a qualitative study of health professionals and their 
experiences with people who use 'ICE' and present to rural and urban Emergency Departments in New South Wales and Queensland, Australia. By sharing and exploring their experiences, these health professionals provide unique perspectives about caring for patients affected by ICE use, and the impact these experiences had on the individual health professional and their colleagues. These insights may inform the development of improved patient care services as well as education programs and employee support initiatives to further develop the capacity and capability of health professionals to provide optimal care to people using ICE requiring emergency care.

\section{METHODS}

Approval to conduct this was granted by the appropriate university ethics review committees (University of New England and University of Tasmania, Australia). Data were collected in Australia over four months (April - July 2016). Participants were recruited through email invitation included in the Australian College of Mental Health Nurses national newsletter, and through professional networks. Inclusion criteria included experience caring for people who used 'ICE' within an Emergency Care environment. Recruitment continued until data saturation occurred (Cleary, Horsfall, \& Hayter, 2014; Fusch \& Ness, 2015).

An experienced mental health nurse researcher (MC) conducted all interviews. Participation was voluntary, and all participants provided written consent. Semi-structured interviews were conducted in person or by telephone depending on participant preference and location (local, interstate, regional areas included). The interview schedule comprised demographic information regarding the individual participant's profession and work setting. The focus of subsequent questions was participant experiences with people affected by ICE and attending ED; the challenges they associated with providing care for these patients, as well as the identification and discussion of the specific support required, both for patients and the health 
professionals caring for them. The duration of interviews ranged from 24 to 66 minutes $(n=$ total 376 minutes). All interviews were digitally recorded and transcribed verbatim.

\section{Data Analysis}

The thematic analysis method was used to analyze data, to ensure that emergent themes were strongly linked to the data (Braun \& Clarke, 2006) and supported the researchers to clarify and understand the topic under investigation (Rebar, Gersch, Macnee, \& McCabe, 2011). Thematic analysis requires a rigorous approach to recognizing and examining patterns within the data. A six step process was undertaken involving: (1) developing familiarity with the data by reading and re-reading the transcripts and notating the text (2) coding the data by labeling excerpts pertinent to the research question and then collating codes and extracts; (3) recognizing themes; (4) appraising themes; (5) naming and explaining themes; and (6) writing the story underpinning the data (Clarke \& Braun, 2013).

Allowing data collection to continue until data saturation and thematic redundancy was achieved enhanced the trustworthiness of the research (Elo et al., 2014; Fusch \& Ness, 2015; Lincoln \& Guba, 1985; Strauss \& Corbin, 1998). Other members of the research team (experienced qualitative researchers) independently reviewed and coded transcripts. This continuous discussion and review by the research team further enhanced rigour during this process (Lincoln \& Guba, 1985). This iterative, inductive process provided the team with the opportunity to become immersed in and understand participants' experiences and perspectives.

In this paper, we present an overview of the participants and findings from the first major theme 'Caring for people who use 'ICE' when presenting to ED'. These results address the research question: What are the experiences of health professionals managing people 
presenting to ED after taking 'ICE'? A companion paper presenting the second theme 'safety and aggression management' is presently under review.

\section{RESULTS}

\section{Participants}

Participants ( $\mathrm{n}=9$ ) were nurses (5), paramedics (2), social worker (1) and a psychotherapist (1). Six were female, the majority worked in urban areas. The number of patient presentations involving 'ICE' use varied across services. Presentations to ED departments varied between participant reports from one per day to fifty per month; two per day to paramedic services and four per day for counselling services.

The major theme, 'caring for people who use 'ICE' when presenting to the emergency department (ED)' was experienced as challenging; at times distressing, and highly complex. Care provision was resource-intensive and the unpredictable behaviours that accompany 'ICE' use meant that multiple staff were often needed to assist with activities that normally would only require a single staff member. However, despite the challenges, participants were committed to providing the best possible care for these patients from their first point of contact through to their discharge. This major theme is comprised of five subthemes. These are: (i) Expecting the unexpected: 'they're just off their heads'; (ii) Complexity of care: 'underlying trauma and emotional dysregulation'; (iii) Connecting and relationships: 'engaging in a calm and helpful way; (iv) Coordinating care and teamwork: 'keeping them quiet and away from everybody'; and, (v) Learning and reflection: 'we need to rethink our treatment options'. These are discussed in detail below.

\section{Expecting the unexpected: "they're just off their heads"}


Participants had come to expect the unexpected when it came to meeting the needs of persons affected by 'ICE'. They described the pressures that patients affected by 'ICE' use could put the ED under. Weekends and holiday periods were reported as 'peak times' for presentations to the ED by people affected by 'ICE' and these are also times that some hospitals operate with some form of reduced services. Participant five described patients sometimes being very distressed and out of control; however, ED staff had to manage these situations within the ED environment, as the patients were not really viewed as needing to be admitted to hospital.

'It's very rare that they will actually admit someone who's on ICE ... because it's like a delirium. It's an acute situation and often they're not psychotic, they're just off their heads.' (P5)

Therefore, ED staff had to provide care as best as they could until the patient was stabilised and calmer and able to be discharged back into the community. Participants felt that an important issue in the provision of optimal initial care for people affected by 'ICE' is the capacity and capability of emergency personnels' immediate responses. This in turn, was felt to be dependent on individual skill, expertise and previous experiences. In addition the volatility and dynamic nature of the environment, as well as the need for external support services such as police and security were viewed as significant factors in providing initial care:

'Mostly the ED staff members ... are not trained to deal with mental health patients ...if somebody becomes acutely aggressive or acutely psychotic and aggressive... normally the police will phone...we get security to come up, to meet the police. The police will normally bring that person in handcuffs, and that's translated to restraints in the emergency, and then they can sedate.' (P4) 
Patients most often presented to the ED in some form of acute mental distress. Participant 7, a paramedic, reported sleep disturbance as a common initiating factor for help-seeking behaviour:

'Because they've been using a lot of ICE they haven't been able to sleep and they start to be - start that psychosis. They can't sleep. They become depressed, incredibly anxious ... They'll identify that they're unwell and that they require transport to hospital or someone else will call concerned for them.' (P7)

Participants felt that patients were more liable to exhibit challenging and unpredictable behaviours when sleep deprived. They believed that sleep deprivation could cause anxiety, extreme fear, paranoia and violence, and because of this there was sometimes the need for police intervention prior to being able to initiate any form of health assessment.

'...At that stage we either need the police assistance just for our safety because you're not sure about where you're going to go with mood swings or violence.' (P7)

Once sedated and stabilised, patients sometimes needed quite long periods of rest and recovery; particularly if they had been on a binge of using, and having long periods of being unable to sleep and rest. This meant that they could effectively 'tie-up' an ED bed for extended periods of time.

'I suppose the people that have used ICE continuously over a period of time, when they arrive in our department, after they've had some sedation, they tend to - they just crash and I suppose they tend to sleep for long periods of time. I'm talking sometimes up to 12 hours a day. They do take up one of our beds. But usually when they come out of their sleep state, they are quite clearly just drug-affected and they're usually discharged from our services.' (P9) 
Generally, once the client presented to ED, a detailed physical assessment process commenced. This physical assessment is necessary to develop a comprehensive clinical history to inform diagnosis and priorities for care but these procedures meant clients affected by 'ICE' use were likely to be seen by a variety of professionals prior to being reviewed by the mental health team. Their clinical presentation may be further complicated where, in addition to 'ICE', patients have also engaged in polysubstance abuse, potentially complicating diagnosis, further delaying full mental health assessment:

'... a nasty thing happens when you mix methamphetamines - if you've been smoking ICE and you take ...gamma-Hydroxybutyric ... liquid ecstasy. The GHB ....will lower your level of consciousness completely...- it's like flicking the light switch off - once their level of consciousness gets to a certain level it's like - it switches back on.' (P7)

While patients were acutely affected by ICE, the mental health team were unable to undertake the assessment that is needed to facilitate the transfer of care to the mental health team. This meant they had to remain in the busy ED environment:

'...they [patients] can't actually be assessed by the mental health team because they're under the influence of the benzos or narcotics. So that means that there's no bed available for them in the mental health unit because they haven't been accepted by a mental healthcare team. So they remain in the emergency department.' (P1)

In response to this dilemma, and to increasing numbers of clients presenting with mental health problems to ED, some participants reported that mental health dedicated beds or units were established within their EDs. These units were established in an attempt to expedite the assessment process:

'So staff from there [mental health] can come and assess patients sooner. Or at least eyeball the patient. Make a primary assessment but then say....contact me when the patient has been medically cleared and I'll come back.' (P2) 


\section{Complexity of care: 'underlying trauma and emotional dysregulation'}

Although the primary reason for client contact with health professionals and ED was related to their use of 'ICE', participants reported many of these clients also had additional underlying mental health and or physical health problems that needed to be simultaneously identified and managed. These complex care needs may be or may not have been known at the time of their admission to ED, making holistic assessment critical to their optimal care. However, difficulties in achieving meaningful assessment sometimes made these decisions very difficult. Participant 9 reflected on the challenges of trying to decide "whether they [patients] have a mental health issue or whether they're simply ICE-affected'.

In addition to mental health concerns, participants reported that other conditions, such as cardiac-related conditions were being seen more frequently among this group of patients:

'The other things that we've been seeing more of have been [non-STEMI infarcts]....trans[ient] ischaemic attacks, tachycardias and arrhythmias. ' (P2)

However, how and where clients affected by ICE and with cardiac conditions could be safely cared for was an important consideration. Their concurrent mental health distress made it challenging to perform appropriate cardiac monitoring. Options for safe care varied according to the situation and to the resources available:

'... somebody with cardiac issues...in acute mental health we would probably put them in seclusion and sedate them. But ... on a general ward,... - I mean you're in a ward with computer and a keyboard and monitoring devices that you would see from a mental health perspective as it being incredibly hazardous... to just special them in that environment is incredibly time and resource intensive.' (P3)

As previously stated, clients taking 'ICE' also sometimes presented with co-occurring mental health conditions that also warranted careful assessment, diagnosis and care strategies: 
'.... we see people who are with reactive depressions, suicidal ideation and intent, and also drug induced psychosis or exacerbation of their existing mental illness'. (P2)

Delirium, paranoia and psychosis were also reported as common co-morbidities by participants, and these co-morbid conditions added to the complexity of providing care in the ED environment. Participants also felt the recognition that some of these patients may also be experiencing underlying trauma was an important skill for health professionals; especially given this history of trauma could further impact patient attitudes and behaviours towards staff:

'Because sometimes we're not just dealing with the behaviours in relation to the emotional dysregulation at the time, but a lot of our guys [patients] have underlying trauma histories... (and are) in an even more emotionally dysregulated state'. (P3)

Participants saw additional complexity in the social situations of some 'ICE' users. The ED environment tends to focus on acute, emergency physical assessment, and so patients can be sent home, with little real follow up in regards to their mental health or social situation:

'the consultant came and said to me oh we're cutting those girls loose. I said but you can't do that. They're only - well one's 14 and one's 15. I said you ring family services. They need to come and get these girls. You just can't put them out on the street for goodness sake. Anyway, the 14 year old was actually under the care of family services, so they said that they would come and pick her up. But the 15 year old, they weren't interested in so the emergency department just discharged her to the street.' (P5)

Participants described patients affected by severe relationship problems including domestic violence and situations where people were led into 'ICE' use through their relationships. Participants recognised that these people faced added difficulties in trying to break away from using 'ICE'. 
'Yesterday I saw a young lady. She is a high user and her husband is using as well, very highly... she wants to change, but he is not ready to change... The reason she is using ICE, I think, is a part of keeping company with him...there are ongoing violent relationships. The lady, she doesn't want to leave because now there are children involved. She stays with the partner in hope that he is changing.' (P2)

Clients presenting to the ED accompanied by sometimes young children represented another layer of complexity requiring intervention by ED staff. Required interventions could include reporting to children's services or contacting other family members to collect children. In this context, participant 2 viewed shame as a particularly significant feature of ICE use, and identified that the effects of feeling shame can be so great, as to deter people from asking for help or using services; providing an additional, further level of complexity to effectively caring for these patients.

'Shame happens before they are using. It happened during the physical withdrawal, detox service and after the detox is complete... shame - is the danger is because shame is people withdraw. They - because there is something wrong as a person. Shame is a very strong negative effect and people try to hide.' (P2)

\section{Connecting and relationships: 'engaging in a calm and helpful way'}

Establishing a rapport was seen as fundamental to developing trust and co-operation between the health care professional and the ED patient affected by 'ICE'. The nature of ED meant that time was of the essence in making an effective, therapeutic connection with the patient. Yet, even in this time-pressured environment, participants identified a crucial need to look beyond each individual's presenting and current behaviours to focus on the humanness and uniqueness of the person: 
'I explain the difference between say a counsellor's role and mine is that, they're in a long-term relationship and I'm speed dating... I have an unconditional positive regard. So that you can actually see people underneath it all; past the behaviours and see the people that are still there.' (P3)

Participants felt that because persons affected by ICE can experience paranoia, and be inclined to misinterpret some interactions, highly developed interpersonal skills such as empathy and clarity in communication were of crucial importance.

'Communication is huge - communication and body language. If they are in a psychosis it's a matter of showing empathy and being quite assertive with what needs to happen and ... that they are foremost a patient and not an attacker.' (P7)

Participants further revealed their empathic stance through reflecting on how they themselves might like to be treated if ever in a similar situation:

'I always think well, if that was me, I would like to be treated with a bit of respect and dignity even though I mightn't remember.' (P5)

Non-verbal communication was also of crucial importance. Being mindful of body language was also a crucial issue, particularly in view of the potential for fear, paranoia and unpredictable behaviour.

'Well most of our encounters with people who have taken ICE are usually - they're combative, initially...... most of them feel that they're being detained, .... illegally. They're unable to be talked to rationally'. (P9)

This meant that taking an assertive, calm demeanour, and trying to establish an authentic connection was considered essential to establishing therapeutic milieu, and the ability to provide effective care for these patients. In working with people affected by ICE, participant 6 aimed: 
'to try and engage the person in a calm and helpful way. But then, the emphasis is on to try and link them and refer them to someone that can then help them, more ongoing.' (P6)

Unfortunately given the addictive nature of ICE it was not uncommon for patients to have multiple, repeated presentations to ED. These repeat encounters between the health professional and the client were sometimes felt as enhancing the development of positive rapport:

'a lot of the times the patient has been admitted previously and so you're either aware of them or you've nursed them before. You sometimes can build rapport that way.'

Family were also viewed as important stakeholders in the patient's care and were sometimes seen as being very supportive not only towards the patient, but also to the ED staff. However, in the case of parental relationships, sometimes there were divergent expectations of care when parents brought a young person to ED:

'So sometimes you can have parents that will bring them in, and they're just desperate for them for treatment. But the person themselves is not.' (P3)

This scenario could be very challenging for staff as they needed to work with the patient and gain the co-operation of the patient for on-going intervention and treatment, and patients did not always want this. Equally challenging for participants were the less supportive attitudes of family members who were drug or alcohol abusers themselves. These family members were considered to be enablers:

'Then you have family who are alcohol abusers or drug abusers themselves and see the presentation as routine, as part of everyday living. They don't see that this is 
behaviour that needs to be rectified, or behaviour that needs to cease... We've had family who bring in drugs, illicit drugs, for family [into the hospital]. '(P1)

Some participants described their frustration around 'revolving door presentations' (P4). These repeated presentations provided challenges for participants in terms of their previous experiences with individual patients, and their ability to connect and reconnect as well as maintaining their objectivity and empathy. Participant 4 reflected on one particular patient, stating:

'... she come(s) in quite aggressive, very paranoid, thinking that our staff are doing something to hurt her. She's actually assaulted a female staff member ...with each admission she vows not to take drugs again... But then she re-presents.' (P4)

\section{Coordinating care and teamwork: 'Keeping them quiet and away from everybody'}

Despite the challenges and the context, participants aimed to provide a safe and calm environment for these patients, who were often highly agitated and in need of a calming milieu. In the context of the busy ED environment, providing this was sometimes very difficult, as the needs of other ED patients and family members also had to be considered:

'I think it's just having somewhere to put them away from excessive stimulus but also away from - there's poor little nannas in the ED. They don't need someone carrying on in the next bed. We all know how much EDs are constrained by budget and by beds and stuff, so it's also not possible for them to always put someone in that kind of place. I suppose that would be the idea. It would just be somewhere that you can keep them quiet and away from everybody.' (P8)

Participants recognised the importance of the whole ED team working together, and saw it as crucial to providing an optimal therapeutic milieu, and to achieving the best possible outcomes for all the clients in their care. This sense of being part of a team was also viewed 
as vitally important to the paramedic participants who work off-site, and may engage with multiple emergency facilities, such as participant 7.

'I think we work well - quite well as a team. Most of the hospitals that we're known to, if we have a patient that's becoming really quite difficult then and that needs to be escalated, you can go to triage and you can go to the nurse manager and you're like okay, this is going to cause issues. What can we do?' (P7)

Participants reported the efforts made in their workplaces to effect strong multidisciplinary team environments. Verbal communication and sharing stories and experiences were seen as contributory to creating a learning environment for all; to better understand the needs of the individual patient, their unique circumstances and responses:

'I think the key here is for everyone, not just nursing staff, to talk to one another. The medical team, mental health team, and all bringing it back to what's in the best interest of the patient.' (P1)

This inclusive view of teamwork and collaboration was considered absolutely crucial to the effective care of patients affected by 'ICE' as they engaged with health services. This collaborative approach meant that personnel were able to effectively advocate for patients to other members of the care team.

'Sometimes it's even advocating on behalf of these guys because a lot of our emergency department specialists just get ticked off. I get a phone call to say, here's one of your patients, no matter what's going on for them. We're identifying them by the drug rather than what the presenting issues actually are.' (P3)

\section{Learning and reflection: 'we need to rethink our treatment options'}

Throughout the interviews, participants reflected on their individual learning needs, and gave their views on the learning needs of others; suggested strategies and other support that could 
enable them to better perform their roles. Participants understood that health professional education doesn't cease on graduation but rather, continues through formal and informal means over the course of their career. Participants felt they had the onus to keep up to date, so that they could better meet the needs of patients experiencing difficulties due to 'ICE'. Through keeping up to date, participants believed they could better know and understand what patients were telling them, as well as having an awareness of relevant evidence based practice and specific therapeutic interventions. Being information literate - that is, being able to readily access information, was seen as important as the information itself:

'Identifying drugs and packaging, slang terms, types of presentations... the new drugs that are coming out ... that are causing these different types of psychoses...their slang terms - and what kind of presentations you get when they present mixed together.'

They acknowledged that informal learning often occurs in clinical contexts and may occur during conversations with patients who often have in-depth knowledge of their situations, and in the case of 'ICE' users, the drug terminology that is used among people using drugs:

'I picked up a kid the other day and he goes oh yeah, - I went out with Molly and his three sisters. He's nodding like I understood - like I knew what he was talking about. Who's Molly? But apparently - Molly is slang these days for ecstasy. ' (P7)

Learning was also reported to occur through collegial instruction, observation of how colleagues reacted to certain situations, and mentoring. Participant one described an occasion, in which she, as a new registered nurse who had recently started work in ED, bent down to the client so that she could make eye contact with them, to try to establish rapport. Her mentor saw this situation differently and intervened: 
'...grabbed me by the shoulder and lifted me up, and later said to me, it's very unsafe what you did because you actually put yourself in a position of harm... like, always stand side on, back to the wall.' (P1)

Planned education through in-service sessions was identified as another means of keeping staff up to date. However, in this instance, participants indicated that trauma was the consistent focus for multidisciplinary in-service sessions within the ED.

'A couple of hospitals run generally more trauma stuff...they'll pull a case out that they've had come in and pull it apart and have everybody contribute. They'll talk about ambulance's role, ED's role, surgeon's role, and we're always welcome to attend those, so there are some things, but it tends to more be trauma.' (P8)

Though they understood the need for this; they also felt that education on 'ICE' and other drug use was necessary. They identified a need for specific in-service education from experts in mental health care to frontline staff dealing with 'ICE' users in ED. In reflecting on experiences of providing care to patients affected by 'ICE', participants felt that current strategies were not as effective as they might be, and felt there was a need for radical revision in treatment.

'I think we need to rethink our treatment options for 'ICE', because it's a different ballgame that we're dealing with here... with methamphetamine... they're scattered, and they're impulsive, and they're high and they're low. There's no consequence or reasoning. So it's really difficult to talk to people about change when they have no consequential reasoning. ' (P3)

Participants also held the view that more patient education was needed, to help people have greater insight into the effects of taking 'ICE'. 
I have been so - felt so frustrated and inadequate that we're losing these kids.

Whether we can get into the schools and give education - but once again it's like that's not going to happen to me, I'm me. I'm indestructible. I'm cool.' (P5).

\section{DISCUSSION}

Emergency Departments are busy environments, often with tired and stressed staff managing a range of highly complex and life-threatening situations. Violent and aggressive behaviours are prevalent within EDs with staff frequently exposed to physical and verbal abuse (Tan, Lopez, \& Cleary, 2015; Taylor \& Rew, 2011) a finding reported in the present study. Methamphetamine use is a significant health care issue, and law enforcement problem and users are more likely to use ambulance transport and be admitted to hospital (Pomerleau et al., 2012; Richards et al., 1999). Thus, health professionals working with and in the ED are positioned as frontline responders for people who use 'ICE'. The impact of patients affected by ICE to the ED was a concern to the participants in this study, in view of the unpredictable behaviour this drug can cause, and the need considerable resources to provide appropriate care. The literature suggests that the use of amphetamines is growing (Cloutier et al., 2013; Dunn et al., 2016; Maxwell, 2005; Richards et al., 1999), and increases in ICE production, trafficking and consumption are reported (Marshall et al., 2012; Maxwell, 2005) despite the efforts of law enforcement agencies.

Patients affected by ICE are often highly complex with multiple health problems. Cardiac complications discussed by participants in the present study are also reported in the literature and are reported as the second major cause of death in people taking methamphetamines (Paratz, Cunningham, \& MacIsaac, 2016; Roxburgh, Ritter, Slade, \& Burns, 2013). This is because, over time, methamphetamine use can be associated with severe physical health problems, including several known cardiac conditions such as methamphetamine-associated 
cardiomyopathy, pulmonary hypertension, hypertension aortic dissection and acute coronary syndromes (Paratz et al., 2016). Using other drugs in combination with methamphetamine can increase the physical effects and the number of methamphetamine-related hospitalisations has rapidly increased, providing tentative evidence of the escalating health consequences (Commonwealth of Australia, 2015).

The present findings demonstrate that each person presenting for care after using 'ICE' is unique, a too is their personal journey with drug use and addiction. How they present from a personal and medical perspective will be influenced by their degree of dependence; previous admissions, their physical and mental health and their experiences with health professionals and services. Accounts conveyed by participants in this current study resonated with other research, which reports people who use methamphetamine to be a diverse group, and the need for staff to use strategies that are targeted towards the different kinds of presentations (Degenhardt et al., 2008; Tompkins-Dobbs \& Schiefelbein, 2011). Participants identified that many of the people presenting to the ED had complex social situations, and some had limited supports. Social networks play a crucial role in reinforcing demand, as the more the drug is used, the more popular it is likely to become (Commonwealth of Australia, 2015). The complex needs of this patient group are also evidenced by current research supporting the need to more effectively reduce the negative health consequences of methamphetamine use, and improve access to appropriate health services (Marshall et al., 2012; Maxwell, 2005).

The attitudes, behaviours and reflective practices of participants presented in the findings are important hallmarks of professional behaviour, compassion and empathy and are central tenets of professional practice (Cleary, Hunt, Horsfall, \& Deacon, 2012). Verbal and nonverbal communication was carefully considered when working with these complex and volatile patients, and this included demonstrating understanding respect, empathy, interest, unconditional positive regard for the person, providing information and explanations, and 
being honest, open and supportive towards the patient and their family. Building rapport and engaging clients is noted elsewhere as essential in the effective treatment of people who use methamphetamine (Rowan-Szal, Joe, Simpson, Greener, \& Vance, 2009).

Health professionals caring for people who use 'ICE' bring to their role, knowledge, skills, attitudes and previous experiences - all of which will influence their interactions with clients and the care they provide to them. However, our participants felt there was a real need for additional educational and policy support for front line staff. A need was identified for "street" name education to enable staff to keep up to date with drugs and identify the types of drugs, slang terms, and types of presentations given issues around poly substance abuse (von, Brecht, \& Anglin, 2002). Tompkins-Dobbs and Schiefelbein (2011) research reports a lack of written policies and procedures to support staff caring for people who use methamphetamine and present to EDs and inconsistencies with the management and treatment of clients (Tompkins-Dobbs \& Schiefelbein, 2011).

Participants discussed some of the challenges of managing people presenting to the ED after taking 'ICE'. Staff could only manage the physical, mental health and behavioural disturbances affecting these patients by working together as a team and through consulting with other health and social care professionals. This attitude to collaborative working is highlighted by Tompkins-Dobbs and Schiefelbein (2011) who suggest the need to alter the way health professionals provide care to people with methamphetamine addiction within EDs. The need for radical revision of how care is provided to these complex patients is seen in the cycle of repeated presentations for emergency care, framed by participants as being like a rotating cycle through the ED doors. Irrespective of the frequency of the presentations, participants expressed the desire to demonstrate care in ways that were meaningful and effective. 
However, many clients were identified as having multiple, complex underlying issues including mental health conditions, challenging social situations, lack of support and trauma. There is some literature suggesting that women with substance use issues often have a history of childhood emotional and sexual trauma (Cleary \& Hungerford, 2015; Dawson, Pritchard, Dean, \& Jackson, 2014; Simpson et al., 2016) and that street drugs including methamphetamine that are accessible and affordable are often used to medicate their untreated emotional and physical pain (Boeri, Tyndall, \& Woodall, 2011).

Polysubstance abuse among methamphetamine users is common and complex (Commonwealth of Australia, 2015; Willi et al., 2016), and there is a need to identify risk factors for these patients (Olthuis, Darredeau, \& Barrett, 2013). To stop the cycle of continued drug use, the literature identifies a need for ED staff to perform substance abuse assessments and ensure adequate follow up, including referral to detoxification and treatment facilities (Boeri et al., 2011). Whilst participants in our study supported and tried to link clients to treatment and detoxification services, where they could, this was not always possible, and sometimes these services were not always readily available. Recommendations to improve care to ICE patients include rolling out training programmes to improve delivery of alcohol and other drug screening as well as brief interventions for ED staff (Commonwealth of Australia, 2015). It is also recommended that this program roll out should be undertaken in consultation with ED staff, professional bodies and other relevant stakeholders.

\section{STRENGTHS AND LIMITATIONS}

As with all research there are strengths and limitations to the present study. What this paper adds are deep insights from front-line providers of care to persons affected by ICE and requiring emergency care. Additional strengths include the multidisciplinary approach, the 
inclusion of staff drawn from several health services across two Australian states, the rich descriptive nature of the interviews, and that many of the participants were experienced clinicians. There may have been some selection bias as participants volunteered to participate in this research and the views of those who elected not to participate may differ. An important limitation of this research was the absence of patient and carer accounts of their experiences. It would be useful to have patient and carer insights into emergency care issues.

\section{CONCLUSION}

This research provides understandings into the impact of the ICE 'epidemic' on health professionals and findings underscore the complexities that ED workers face in providing effective care to patients affected by ICE. Care provision is highly resource intensive and staff support and education is crucial. Building rapport and being able to engage clients effectively to support recovery for the individual and their family merit greater attention and further research. This includes research into engagement and retention of methamphetamine users into treatment, evidence-based treatment options for methamphetamine and evaluation of training models (Commonwealth of Australia, 2015). 


\section{REFERENCES}

Australian Institute of Health and Welfare. (2014). National Drug Strategy Household Survey detailed report 2013. Drug statistics series no. 28. Cat. no. PHE 183. Canberra: AIHW.

Boeri, M. W., Tyndall, B. D., \& Woodall, D. R. (2011). Suburban Poverty: Barriers to Services and Injury Prevention among Marginalized Women who Use Methamphetamine. Western Journal of Emergency Medicine, 12(3), 284-292.

Braun, V., \& Clarke, V. (2006). Using thematic analysis in psychology. Qualitative Research in Psychology, 3(2), 77-101.

Bunting, P. J., Fulde, G. W., \& Forster, S. L. (2007). Comparison of crystalline methamphetamine ("ice") users and other patients with toxicology-related problems presenting to a hospital emergency department. Medical Journal of Australia, 187(10), 564-566.

Clark, J. (2008). CNE: The danger next door: methamphetamine. RN/AHC Media Home Study Program CE CENTER, 71(5), 22-27. Available at: http://www.modernmedicine.com/modernmedicine/content/cne-danger-next-door-methamphetamine. Accessed: September 12 2016.

Clarke, V., \& Braun, V. (2013). Teaching thematic analysis: Overcoming challenges and developing strategies for effective learning. The Psychologist, 26(2), 120-123.

Cleary, M., Horsfall, J., \& Hayter, M. (2014). Data collection and sampling in qualitative research: does size matter? Journal of Advanced Nursing, 70(3), 473-475. 
Cleary, M., \& Hungerford, C. (2015). Trauma-informed Care and the Research Literature: How Can the Mental Health Nurse Take the Lead to Support Women Who Have Survived Sexual Assault? Issues in Mental Health Nursing, 36(5), 370-378.

Cleary, M., Hunt, G. E., Horsfall, J., \& Deacon, M. (2012). Nurse-patient interaction in acute adult inpatient mental health units: a review and synthesis of qualitative studies. Issues in Mental Health Nursing, 33(2), 66-79.

Cloutier, R. L., Hendrickson, R. G., Fu, R. R., \& Blake, B. (2013). Methamphetamine-related psychiatric visits to an urban academic emergency department: an observational study. The Journal of Emergency Medicine, 45(1), 136-142.

Commonwealth of Australia. (2015). Department of the Prime Minister and Cabinet, Final Report of the National Ice Taskforce. Canberra: Commonwealth of Australia.

Dawson, A., Pritchard, C., Dean, S., \& Jackson, D. (2014). Towards Gender-responsive, Trauma-informed Care for Substance Use Disorders and PTSD: Evidence to Inform Non-government Services in Australia. The International Journal of Interdisciplinary Social and Community Studies, 8(1), 67-91.

Degenhardt, L., Roxburgh, A., Black, E., Bruno, R., Campbell, G., Kinner, S., \& Fetherston, J. (2008). The epidemiology of methamphetamine use and harm in Australia. Drug and Alcohol Review, 27(3), 243-252.

Dunn, K. E., Barrett, F. S., Yepez-Laubach, C., Meyer, A. C., Hruska, B. J., Petrush, K., . . . Bigelow, G. E. (2016). Opioid Overdose Experience, Risk Behaviors, and Knowledge in Drug Users from a Rural versus an Urban Setting. Journal of Substance Abuse Treatment, 71, 1-7.

Elo, S., Kääriäinen, M., Kanste, O., Pölkki, T., Utriainen, K., \& Kyngäs, H. (2014). Qualitative content analysis. Sage Open, 4(1), 1-10. 
Fusch, P. I., \& Ness, L. R. (2015). Are we there yet? Data saturation in qualitative research. The Qualitative Report, 20(9), 1408-1416.

Grant, K. M., LeVan, T. D., Wells, S. M., Li, M., Stoltenberg, S. F., Gendelman, H. E., . . . Bevins, R. A. (2012). Methamphetamine-Associated Psychosis. Journal of Neuroimmune Pharmacology, 7(1), 113-139.

Heilbronn, C. (2013). Call-outs to ice users triple as crystal meth impacts grow. The Queensland Times, Life Style.

Kinner, S. A., Kinner, S. A., Degenhardt, L., Kinner, S. A., \& Degenhardt, L. (2008). Crystal methamphetamine smoking among regular ecstasy users in Australia: increases in use and associations with harm. Drug and Alcohol Review, 27(3), 292-300.

Lee, N. (2013). Explainer: methamphetamine use and addiction in Australia. The Conversation. The Conversation, 23 April 2013. Available at: https://theconversation.com/explainer-methamphetamine-use-and-addiction-inaustralia-13280. Accessed: September 122016.

Lee, N. (2015). Are we in the midst of an ice epidemic? A snapshot of meth use in Australia. The Conversation, 8 April 2015. https://theconversation.com/are-we-in-the-midst-ofan-ice-epidemic-a-snapshot-of-meth-use-in-australia-39697. Accessed: September 12 2016.

Lincoln, Y., \& Guba, E. (1985). Naturalistic Inquiry. Newbury Park, CA: Sage.

Lloyd, B., Matthews, S., \& Gao, C. (2014). Trends in alcohol and drug related ambulance attendances in Victoria 2012/13. Victoria: Turning Point.

Marshall, B. D., Grafstein, E., Buxton, J. A., Qi, J., Wood, E., Shoveller, J. A., \& Kerr, T. (2012). Frequent methamphetamine injection predicts emergency department utilization among street-involved youth. Public Health, 126(1), 47-53. 
Maxwell, J. C. (2005). Emerging research on methamphetamine. Current Opinion in Psychiatry, 18(3), 235-242.

Olthuis, J. V., Darredeau, C., \& Barrett, S. P. (2013). Substance use initiation: the role of simultaneous polysubstance use. Drug and Alcohol Review, 32(1), 67-71.

Paratz, E. D., Cunningham, N. J., \& MacIsaac, A. I. (2016). The Cardiac Complications of Methamphetamines. Heart, Lung and Circulation, 25(4), 325-332.

Pomerleau, A. C., Sutter, M. E., Owen, K. P., Loomis, E., Albertson, T. E., \& Diercks, D. B. (2012). Amphetamine Abuse in Emergency Department Patients Undergoing Psychiatric Evaluation. The Journal of Emergency Medicine, 43(5), 798802.

Rebar, C., Gersch, C., Macnee, C., \& McCabe, S. (2011). Understanding nursing research: Using research in evidence-based practice (3rd ed.). Philadelphia: Lippincott Williams.

Richards, J. R., Bretz, S. W., Johnson, E. B., Turnipseed, S. D., Brofeldt, B. T., \& Derlet, R. W. (1999). Methamphetamine abuse and emergency department utilization. Western Journal of Medicine, 170(4), 198-202.

Rowan-Szal, G. A., Joe, G. W., Simpson, D. D., Greener, J. M., \& Vance, J. (2009). Duringtreatment Outcomes among Female Methamphetamine-Using Offenders in Prisonbased Treatments. Journal of Offender Rehabilitation, 48(5), 388-401.

Roxburgh, A., Ritter, A., Slade, T., \& Burns, L. (2013). Trends in Drug Use and Related Harms in Australia, 2001 to 2013. Sydney, National Drug and Alcohol Research Centre, University of New South Wales. Accessed from the NDARC website: https://ndarc.med.unsw.edu.au/sites/default/files/ndarc/resources/Australian\%20Drug \%20Trends\%202001\%20to\%202013.pdf 
Simpson, J. L., Grant, K. M., Daly, P. M., Kelley, S. G., Carlo, G., \& Bevins, R. A. (2016). Psychological Burden and Gender Differences in Methamphetamine-Dependent Individuals in Treatment. Journal of Psychoactive Drugs, 48(4), 261-269.

Strauss, A., \& Corbin, J. (1998). Basics of qualitative research: Techniques and procedures for developing grounded theory. Newbury Park, CA: Sage Publications, Inc.

Tan, M. F., Lopez, V., \& Cleary, M. (2015). Nursing management of aggression in a Singapore emergency department: A qualitative study. Nursing \& Health Sciences, $17(3), 307-312$.

Taylor, J. L., \& Rew, L. (2011). A systematic review of the literature: workplace violence in the emergency department. Journal of Clinical Nursing, 20(7-8), 1072-1085.

Tompkins-Dobbs, K., \& Schiefelbein, J. (2011). Emergency Department Policies and Procedures for Treatment of Patients Abusing Methamphetamine. Journal of Emergency Nursing, 37(5), 437-443.

von, M. C., Brecht, M. L., \& Anglin, M. D. (2002). Use ecology and drug use motivations of methamphetamine users admitted to substance abuse treatment facilities in Los Angeles: an emerging profile. Journal of Addictive Diseases, 21(1), 45-60.

Willi, T. S., Honer, W. G., Thornton, A. E., Gicas, K., Procyshyn, R. M., Vila-Rodriguez, F., . . Barr, A. M. (2016). Factors affecting severity of positive and negative symptoms of psychosis in a polysubstance using population with psychostimulant dependence. Psychiatry Research, 240, 336-342. 